\title{
A tradução da
} plataforma governamental VLibras e a acessibilidade de surdos no ensino superior

The translation of the government platform VLibras and the accessibility of deaf people in higher education

Bárbara Silveira Baptista de OLIVEIRA (UFV) barbara.baptista@ufv.br

Ana Luisa Borba GEDIEL (UFV) ana.gediel@ufv.br

Gabriela da Silva PIRES (UFV) gabriela.pires@ufv.br

Recebido em: 27 de jan. de 2021. Aceito em: 09 de jun. de 2021.

OLIVEIRA, Bárbara Silveira Baptista de; GEDIEL, Ana Luisa Borba; PIRES, Gabriela da Silva. A tradução da plataforma governamental VLibras e a acessibilidade de surdos no ensino superior. Entrepalavras, Fortaleza, v. 11, n. 3, e2230, p. 32-51, set.-dez./2021. DOI: $10.22168 / 2237-6321-32230$

Resumo: Neste artigo, ancorado nas propostas de Quadros \& Karnopp (2004) e Brito (1995), analisamos a tradução semiautomática da plataforma VLibras, levando em consideração a adequação sintática da tradução do português para a Libras, por meio da tradução de artigos científicos de diferentes áreas, focando nos desafios do acesso e permanência das pessoas surdas no ensino superior. Foi utilizada a metodologia qualitativa para a realização da análise do corpus, descrição e adequação dos elementos gramaticais da língua de modalidade oral auditiva para a visuoespacial, em formato de glosa. Para tanto, com o objetivo de analisar o processo de tradução automática, propusemos a seguinte segmentação da análise linguística:

(i) flexão verbal; (ii) organização sintática; (iii) pontuação. Como resultados, percebemos que há padronizações na tradução que geram incoerências e erros. Entendemos que a maior parte dos erros de tradução fornecidos pelos tradutores automáticos é devido à falta de valorização dos aspectos linguísticos da Libras e seu detrimento em relação aos aspectos gramaticais do português. Para alterar esse quadro, é necessário um maior aprofundamento de estudos como este para averiguar os erros, acertos e buscar soluções e, assim, auxiliar o aprimoramento de ferramentas de tradução automática.

Palavras-chave: Tradução. Tradução automática. Libras. 
Abstract: In this article, based on Quadros \& karnopp (2004) and Brito (1995), we analyzed the semi-automatic translations of the VLibras platform. We considered the syntax adequation of the translation from Portuguese to Libras through scientific articles from different areas, focusing on the challenges of access and permanence of death students on higher education. A qualitative methodology was used to analyze the corpus and describe the adequation of the grammatical elements of the oral hearing language to the spatial visual language. In order to analyze the automatic translation process, we proposed the following division of linguistic analysis: (i) verbal inflection; (ii) synthetic organization; (iii) punctuation. As a result, we found that there is a pattern on the translation that generates mistakes. We understand that most errors from the automatic translation were due to the lack of consideration of the grammatical aspects of Libras concerning Portuguese. Changing this scenario requires a deeper understanding of studies such as this, aiming to investigate the errors, the hits, and search solutions to improve automatic translation tools.

Keywords: Translation. Automatic translation. Libras.

\section{Introdução}

Nos últimos anos, verifica-se um grande crescimento de aplicativos de tradução automática do português para Libras. Nesse contexto, as diferenças linguísticas, principalmente as divergências sintáticas entre as línguas, devem ser consideradas no momento da tradução, pois estas são a chave para o entendimento da sentença.

Esta pesquisa usufruiu da elaboração da plataforma Inclua que visa à criação de um sistema gerador de glosas automáticas, a partir do texto em português, para auxiliar os surdos nos estudos. Desse modo, tem o intuito de contribuir com a acessibilidade e a inclusão, visando à permanência de estudantes surdos no ensino superior. Ainda, essa discussão visa a auxiliar o cenário de Tecnologias Assistivas (TA). Compreendemos TAs como as soluções tecnológicas adequadas às pessoas com deficiência, voltadas para melhorar as condições de acesso ao ensino e, consequentemente, à inclusão (ITS BRASIL, 2012).

Portanto, por meio da plataforma governamental de tradução VLibras, buscamos possíveis contribuições para a incorporação de glosas e sinais. Em específico, esse processo visa a auxiliar na própria plataforma, através da verificação da adequação de frases que apresentam erros sintáticos na tradução.

O VLibras possui um sistema de glosas já elaborado, que permite o processo de tradução simultânea de uma frase em língua portuguesa para a Libras, mediado por um avatar ${ }^{1}$. Entendemos que há limitações no que tange à tradução de períodos simples e períodos

${ }^{1}$ No contexto estudado, um avatar é um corpo cibernético utilizado para traduzir termos de uma língua oral para uma língua de sinais. 
v. 11 (3) 32-51 set-dez 2021

compostos do português-Libras e da Libras-português. Isso limita o uso da ferramenta no contexto pedagógico, pois os textos podem apresentar erros na tradução que venham a comprometer o entendimento do texto e/ou sentenças pelos alunos/pessoas Surdas². Então, quais são as adequações sintáticas necessárias para uma transposição linguística entre a Libras e o português?

Desse modo, a presente pesquisa objetivou analisar a tradução fornecida pela plataforma VLibras, a fim de auxiliar no cenário de acesso e permanência das pessoas surdas no ensino superior. Para tanto, o projeto visa verificar a adequação sintática da tradução de Libras para o português e do português para a Libras pelo aplicativo VLibras. Assim, para analisar a tradução do aplicativo, delimitamos um corpus e o traduzimos pela plataforma, analisando manual e cuidadosamente todas as sentenças traduzidas. Dessa maneira, usufruímos da metodologia qualitativa para a análise, descrição e adequação dos elementos gramaticais da língua portuguesa para a Libras.

Em relação aos resultados da pesquisa, observamos, por meio da revisão da tradução das frases fornecidas pelo aplicativo, a importância de fomentar melhorias no processo de formação de frases em Libras. Em relação aos aspectos linguísticos, o software apresentou incidências na tradução que comprometem a clareza das sentenças, por mostrar uma soberania da estrutura sintática do português em detrimento da Libras, além do uso em escala da datilologia.

\section{Os estudos da sintaxe da Libras}

Para explicar a sintaxe da Libras, partimos da afirmação "o estabelecimento nominal e o uso do sistema pronominal são fundamentais para as relações sintáticas" (QUADROS\& KARNOPP, 2004, p. 127). Essa citação se associa à sintaxe espacial, que caracteriza a organização sintática da Libras, a qual é feita a partir da determinação de um local no espaço de sinalização. Nesse sentido, a sinalização é caracterizada pelos referentes, que podem estar fisicamente presentes ou não (nesse último caso, a marcação é feita a partir de pontos imaginários no espaço).

\footnotetext{
2 A discussão trazida pelo antropólogo Magnani (2007) expõe que o termo "Surdo" e "Comunidade Surda", com a primeira letra em caixa alta, foram convencionados para marcar a diferença, a fim de que houvesse uma afirmação da identidade Surda sem remeter-se à dimensão da deficiência, voltando aos aspectos culturais e/ou políticos da condição de surdez que pertence à dimensão da diferença.
} 
As autoras listam meios de marcação que auxiliam o estabelecimento do fator espacial, sendo eles: a realização do sinal em um local particular; o direcionamento da cabeça, dos olhos e, às vezes, do corpo na direção relevante, juntamente à realização do sinal; o uso da apontação ostensiva antecedente ao sinalizar; o uso de um pronome a partir da apontação ostensiva, que se localiza em um ponto particular; o uso de um classificador nessa posição, e o uso de um verbo direcional (também chamado de verbo de concordância), incorporando os referentes previamente introduzidos no espaço.

Definidos os princípios da gramática espacial, passamos para os fundamentos da organização sintática da Libras. Partindo de estudos a respeito da ordem na American Sign Language (ASL) (STOKOE, 1960), estabeleceu-se que a ordem gramatical da Libras é SVO (sujeito-verboobjeto). Entretanto, há desvios dessa ordem básica, que são explicados por fatores lexicais e gramaticais. A topicalização (Top), muito utilizada na Libras, é apontada como um dos principais fatores de alteração da ordem na língua, uma vez que a posição de tópico situa-se na posição mais alta da sentença. Reporta-se ainda a alteração na ordem por meio de processos como focalização, elevação do objeto em construções de concordância, além da possibilidade de as funções sujeito e objeto terem realização nula com verbos ditos de concordância (BRITO, 1995).

Depreende-se, portanto, uma assimetria entre orações com verbos sem concordância e com concordância no que se refere à ordem de constituintes. Para entender esse processo, é importante diferenciar os tipos de verbo. Quadros e Karnopp (2004) apontam que na Libras há pelo menos dois tipos de verbos: os verbos sem concordância e os verbos com concordância.

Os verbos sem concordância não se flexionam em pessoa e número, mas exigem argumentos explícitos, como por exemplo, o verbo "gostar": <ELA GOSTAR CHOCOLATE>, sendo "ela" o primeiro argumento e "chocolate" o segundo. Já os verbos com concordância são flexionados em pessoa e número, possuindo, ainda, marcações não manuais e movimentos direcionais, como por exemplo, o verbo "ajudar". Caso a sentença seja apenas <1AJUDAR2 >, está gramaticalmente correta, pois os números 1 e 2 marcam o direcionamento da mão, que irá apontar para os argumentos sem necessidade de marcá-los explicitamente no discurso.

Desse modo, caso a oração possua um verbo simples, podemos identificar sua flexão a partir do sujeito da oração, o qual será 
V. $11(3)$

32-51

set-dez 2021 seu primeiro argumento, pois esse tipo de verbo respeita a estrutura. Verifica-se também que verbos com concordância podem preceder a negação, diferentemente de verbos sem concordância, que só o fazem na presença de um auxiliar, definido como "uma expressão pura de concordância estabelecida através do movimento de um ponto a outro" (QUADROS \& KARNOPP, 2004, p. 163).

Acreditamos que os aspectos da sintaxe da língua portuguesa possuem também grande importância para o efetivo entendimento deste trabalho, visto que é necessário discernir a organização sintática entre a língua portuguesa e a Libras.

Alguns aspectos gramaticais da sintaxe do português

Para a análise da estrutura sintática oracional, é necessário tomar como base que a constituição frasal ocorre por meio de combinações sintagmáticas. A associação das palavras em blocos de sentido é entendida como um sintagma. Para Souza e Silva \& Koch (2011, p. 17), "sintagma consiste num conjunto de elementos que constitui uma unidade significativa dentro da oração e que mantêm entre si relações de dependência e de ordem".

Assim, "os lindos pássaros azuis" e "aves" são de igual maneira entendidos como sintagmas nominais, uma vez que atuam como unidades de igual categoria e função sintática. Podem, por exemplo, ser objeto direto de um verbo (predicador verbal) como "ver":

(1) "João viu os lindos pássaros azuis."

(2) "João viu aves."

Em se tratando da estruturação sintática oracional, temos em português a ordem SVO (sujeito-verbo-objeto), entendida como espontânea e natural.

Para que a comunicação ocorra, é necessário saber organizar o vocabulário em uma frase. De acordo com Márcia Cançado (2005), essa organização sintática é o fator mais importante a ser considerado no contexto comunicativo. Assim, chamamos atenção para a sintaxe de colocação, ou seja, "aquela que trata da maneira de dispor os termos dentro da oração e da oração dentro do período" (BECHARA, 2009, p. 485).

Para entendermos melhor o processo comunicativo e gerador de sentenças da língua portuguesa, devemos ter em mente que a escolha 
da ordenação dos constituintes de uma sentença está interligada com a intenção do falante. Desse modo, adicionamos que, apesar da ordem SVO ser considerada a ordem canônica da língua portuguesa, ela pode sofrer alterações e até mesmo uma inversão, que é vista como um recurso que serve para "dar maior ênfase à ação praticada do que a quem a praticou" (BAGNO, 2017, p. 134).

Nesse sentido, Negrão, Scher \& Viotti (2017, p. 91 e 92) demonstram processos linguísticos que justificam a inversão da ordem SVO, sendo alguns deles a topicalização, a clivagem e a passivação. Para ilustrar esses processos, utilizaremos os mesmos exemplos que as autoras trouxeram em sua obra, tomando o exemplo (3) como ponto de partida.

(3) "O João vai comprar o último livro do Chomsky na Bordersamanhã" (NEGRÃO et. al., 2017, p. 91).

Sendo a topicalização o posicionamento dos vários constituintes no início da oração, as sentenças oriundas desse processo podem tomar a seguinte forma:

(4) "Amanhã, o João vai comprar o último livro do Chomsky na Borders" (NEGRÃO et. al., 2017, p. 91).

Ainda, há a operação da clivagem, em que os constituintes são descolados e "ensanduichados" entre o verbo "ser" e o conectivo "que" e movidos para a posição frontal, como em:

(5) "É o João que vai comprar o último livro do Chomsky na Borders amanhã" (NEGRÃO et. al., 2017, p. 91).

Já a passivização corresponde à adaptação de uma sentença que está na voz ativa para a voz passiva, ou seja, mudança do objeto da oração ativa para o agente da oração passiva. Aplicando a passivização, o exemplo é alterado para:

(6) "O último livro do Chomsky vai ser comprado pelo João amanhã na Borders'” (NEGRÃO et. al., 2017, p. 91).

A partir dessas apresentações preliminares, é visível que a ordem base da organização dos constituintes está diretamente ligada às relações semântico-pragmáticas, uma vez que parte do princípio de que a gramática é moldada pelo próprio discurso. 
V. 11 (3)

32-51

set-dez 2021

Assim, concordamos com Neves (1997, p. 24), para quem a língua é um instrumento de interação verbal, de forma que "uma sentença que presumivelmente contenha apenas informações semânticas e que não apresente função pragmática realmente não existe na comunicação" e, de forma descontextualizada, só seria postulada com finalidade analítica.

As traduções do português para a Libras

Os processos tradutórios e linguísticos vêm sendo debatidos com maior frequência nos últimos anos. Acredita-se que estudos a respeito de traduções podem contribuir com discussões sobre a linguística da Libras, pensando na produção de sentidos e efeitos sofridos por eles; ainda, implicam a investigação das condições e dos aspectos linguísticos e discursos que se articulam a uma determinada exterioridade, constituindo um todo, que vem a configurar o trabalho da linguagem (STUMPF \& QUADROS, 2018).

A tradução do português para a Libras, ou vice-versa, é um tipo de tradução intermodal, pois consiste na tradução de línguas que possuem modalidades diferentes. A Libras se aproveita do espaço, do corpo e da visão para se consolidar, sendo categorizada como uma língua visuoespacial, enquanto a língua portuguesa se enquadra na categoria oral-auditiva, por ocorrer através de recursos orais como sons relacionados à fala (QUADROS \& KARNOPP, 2004).

Lefevere e Bassnett (1990) procuram desconstruir uma concepção essencialista que se tinha acerca da tradução, como ideia de que o princípio de equivalência está na correspondência de palavra por palavra de uma língua-fonte para a língua-alvo. Os autores argumentam que uma abordagem linguística da tradução pressupõe a existência de uma equivalência entre a língua-fonte e a língua-alvo. Além disso, acredita-se na infalibilidade da tradução, em uma teoria objetiva da língua/linguagem.

Na concepção tertium comparationis, o tradutor estaria isento de qualquer influência subjetiva e, por isso, forneceria uma tradução "pura", fidedigna, livre de qualquer ruído da cultura e da sociedade da qual ele faz parte. Nessa mesma abordagem da tradução, caberia ao tradutor ter conhecimento profundo das duas línguas - língua fonte e língua alvo-e, no ato de traduzir, ele utilizaria os parâmetros linguísticos para realizar a tradução de uma obra. 
Portanto, é importante que na tradução de quaisquer línguas estejam presentes as normas, culturas e valores da língua-alvo. Cabe ao tradutor fazer essa transposição para que a tradução seja clara para o falante. Na Libras, o trabalho de Segala, Quadros e Souza (2018) trata de possíveis estranhamentos que podem ocorrer caso a tradução não se adéque.

Desse modo, são listados cinco estranhamentos em relação aos quais deve-se ficar atento na tradução da língua portuguesa para a Libras. São eles: o português sinalizado, os empréstimos linguísticos, os neologismos, a linguagem de ouvintes e os aspectos formais. É importante chamar atenção para os empréstimos linguísticos das línguas de sinais, sendo estes as palavras que nascem por outras línguas e são emprestadas pela língua visuoespacial, podendo a fonte ser da mesma modalidade ou da modalidade oral-auditiva.

Para esta última, a Libras utiliza o recurso do alfabeto manual, lançando mãos de termos e algumas palavras que não existem na Libras. Ainda, o alfabeto manual (datilologia) é utilizado, principalmente, para soletrar nomes, endereços e palavras estrangeiras. Entretanto, por se tratar de um empréstimo, o uso demasiado da datilologia pode prejudicar o entendimento da língua-alvo (RAMOS, 2008).

Além do uso abundante do alfabeto manual, os aspectos formais também ocuparam um grande espaço na pesquisa. Estes equivalem ao não seguimento da estrutura gramatical da língua-alvo, ou seja, a não consideração dos aspectos sintáticos, morfológicos e fonológicos da Libras. Assim, algumas traduções seguem a estrutura da língua portuguesa, ignorando a sintaxe espacial, os processos morfológicos da Libras e até os parâmetros fonológicos.

É importante se atentar aos estranhamentos no processo tradutório, pois esses comprometem o entendimento da tradução, valorizando o português em detrimento da Libras.

\section{Percurso metodológico}

Para o presente estudo, foi utilizada a metodologia qualitativa. Assim, foi feito o mapeamento empírico de artigos encontrados em periódicos da Universidade Federal de Viçosa (UFV), local em que esta pesquisa é realizada.

No total, a instituição de ensino superior (IES) possui 21 revistas vinculadas a seus centros, sendo oito vinculadas ao Centro de 
V. 11 (3) 32-51 set-dez 2021
Ciências Humanas, sete ao Centro de Ciências Agrárias, duas ao Centro de Ciências Biológicas, uma ao Centro de Ciências Exatas, uma vinculada ao colégio de aplicação COLUNI e uma interdisciplinar. De todas as revistas, foram selecionadas duas para a pesquisa, sendo umada área das Ciências Humanas, Letras e Artes e a outra de Ciências Exatas.

As revistas selecionadas foram a Revista de Ciências Humanas e The Journal of Engineering and Exact Sciences. A escolha pela primeira,dentre as várias revistas que abarcam a área de Ciências Humanas, Letras e Artes, ocorreu por ela possuir o maior Qualis CAPES do quadriênio 2012-2016 (B1). Já a escolha pela revista The Journal of Engineering and Exact Sciences é justificada por esse ser o único periódico vinculado exclusivamente ao Centro de Ciências Exatas da UFV.

Foram selecionadas as edições mais recentes das revistas para serem o corpus deste trabalho. Ambas apresentaram 10 artigos científicos, o que facilitou a equivalência da proporção traduzida. A partir do cálculo dos 3\% das revistas, feito manualmente por meio de uma proporção matemática, selecionamos dois artigos como corpus: o da Revista do Centro de Ciências Humanas, intitulado "Tradução comentada do poema em língua brasileira de sinais 'Amor à primeira vista'"”, das autoras Marília Duarte da Silva e Neiva de Aquino Albres, publicado em 2018, e o artigo da Revista de Ciências Exatas, intitulado "Projeto de um sistema de suspensão para um veículo tipo Fórmula SAE elétrico", escrito por Cabral et. al e publicado no ano de 2019. O corpus analisado manualmente a partir dos dois artigos foi constituído de 3.405 palavras.

Após esse levantamento, foi feita a tradução no aplicativo VLibras, sendo inserido um parágrafo por vez para o avatar traduzir. Após a tradução do corpus, verificamos se o VLibras era capaz de traduzir de maneira altamente satisfatória as frases dos gêneros acadêmicos. Essa análise foi feita de forma manual, averiguando separadamente cada sentença traduzida pelo aplicativo e observando se ela estaria de acordo com as normas da Libras. Foram considerados para este trabalho: (i) a flexão dos verbos; (ii) a organização sintática; (iii) a apresentação da pontuação.

Tal processo metodológico possibilitou identificar os sintagmas nas sentenças e verificar o processo de transposição sintática da língua portuguesa para Libras por meio de glosas.

Tomando como parâmetro a percepção linguística (pela proficiência linguística em Libras e língua portuguesa), propomos descrever e analisar a adequação da tradução na plataforma VLibras. 
Sobre o VLibras, software utilizado na pesquisa

O VLibras é resultado de uma parceria entre o Ministério da Economia (ME), por meio da Secretaria de Governo Digital (SGD) e a Universidade Federal da Paraíba (UFPB). Em seu site, ele é definido como um conjunto de ferramentas computacionais de código aberto, que traduz conteúdos digitais para Libras, tornando os conteúdos mais acessíveis para pessoas surdas.

O software possui a proposta de "traduzir em tempo real o conteúdo digital exposto na web ou em outro suporte de comunicação para a Linguagem Brasileira de Sinais (LIBRAS)" (BEZERRA et al., p. 2, 2017). Assim, o aplicativo ajudaria a democratizar o acesso à informação e aos meios digitais, amenizando as barreiras comunicacionais dos Surdos.

Para utilizar o software, deve-se, primeiramente, fazer o download em seu navegador, computador ou smartphone. Como a presente pesquisa foi realizada com base no software em seu formato fornecido pelo computador, somente este será explicitado aqui. Após feito o download, ao abrir o aplicativo, nos depararemos com a seguinte tela:

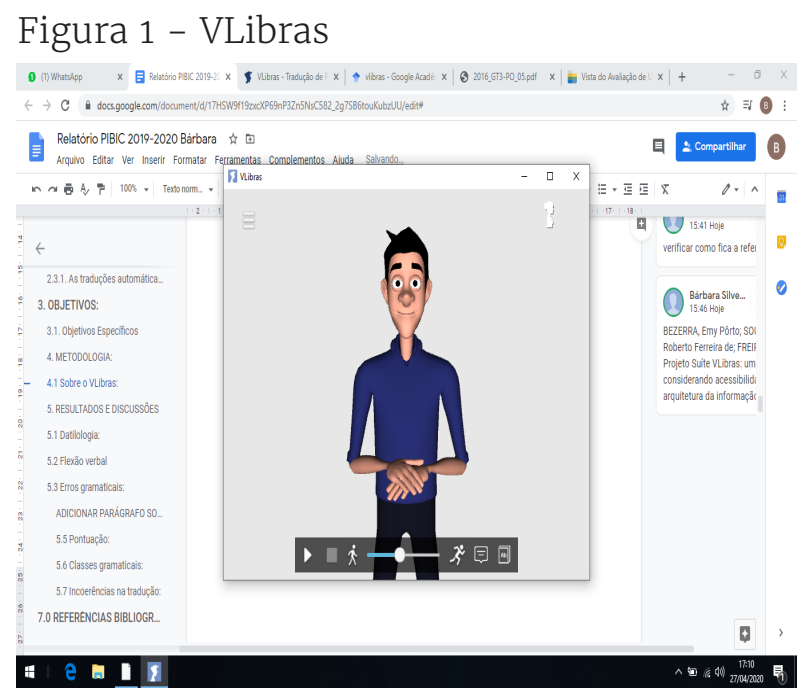

Fonte: VLibras (https://www.vlibras.gov.br/)

Abaixo do avatar encontra-se uma barra de opções, sendo que o triângulo é referente ao play, ou seja, ao controle de início e pausa da sinalização. Ao seu lado, há um quadrado referente ao reinício da sinalização em posição de começo. Seguindo, há uma barra correspondente à velocidade em que o avatar irá sinalizar, podendo 
V. 11 (3)

32-51

set-dez 2021

ser controlada por meio do posicionamento da bola: quando está mais próxima do lado esquerdo indica que a sinalização será feita de forma mais lenta e mais próxima do lado direito indica que a sinalização ganhará velocidade. Há também um balão de fala que, caso selecionado, adiciona legenda em português acompanhando a sinalização. Ainda há uma imagem de livro que, se selecionada, abrirá um dicionário.

A função de dicionário não foi utilizada ou avaliada nesta pesquisa, uma vez que, para a coleta dos dados, utilizamos apenas a tradução simultânea. Para tal, selecionamos na página da web um parágrafo por vez dos artigos escolhidos e pressionamos o botão de play para iniciar a sinalização, como explicado no site do VLibras. Ressaltamos que a presente pesquisa foi protagonizada pela versão do VLibras baixada em 12 de dezembro de 2019.

\section{Flexão verbal nas traduções português-Libras}

Foi possível observar alguns padrões utilizados pelo aplicativo na tradução das sentenças. Um deles foi o modo com que os verbos passaram a ser flexionados temporalmente. Assim, a maior parte dos verbos foi colocada no infinitivo, seguindo o padrão verbal das glosas (QUADROS, PATRÍCIA, REZENDE, 2008). Segue abaixo um exemplo de como os verbos foram majoritariamente flexionados na tradução fornecida e, em seguida, a tradução proposta pelas autoras:

(7) Texto original da Revista de Ciências Exatas:

Como objetivo específico, visa-se criar uma base sólida do procedimento de projeto para os futuros membros da equipe e amparar durante a construção física do Protótipo GX-01E, que participará da competição Fórmula SAE Brasil 2018.

(8) Glosa do VLibras:

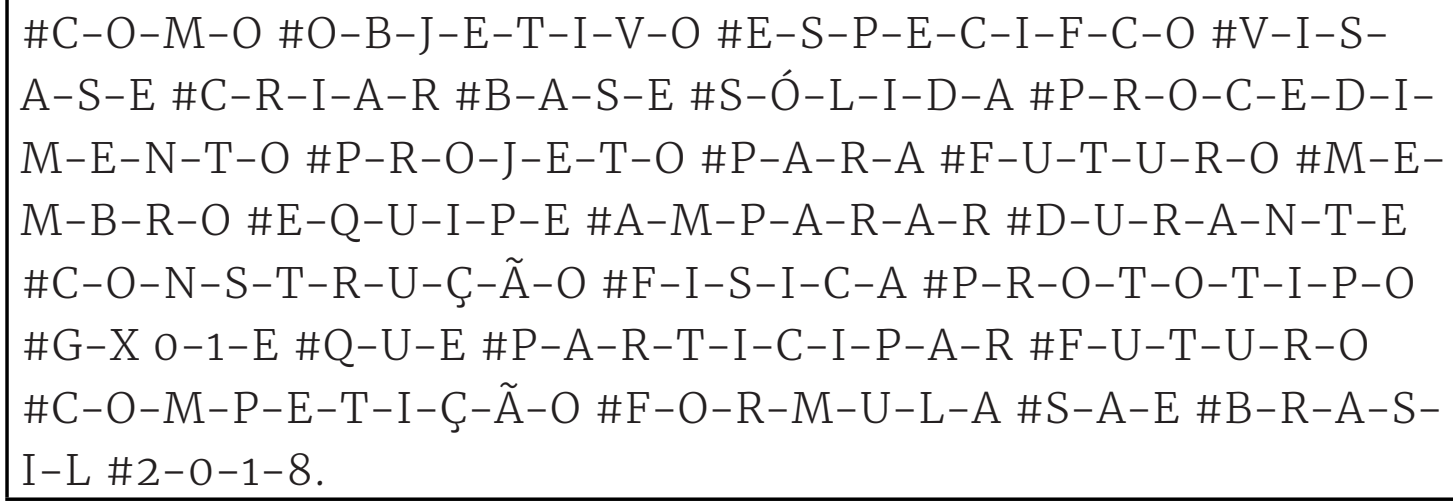


(9) Glosa das autoras:

OBJETIVO ESPECÍFICO CRIAR CLARO PROCEDIMENTO DE PROJETO PARAPESSOAS FUTURO ENTRAR EQUIPE E AJUDAR CONSTRUIR PROTÓTIPO \#G-X 0-1-E PARA FUTURO PARTICIPAR COMPETIÇÃO \#F-O-R-M-U-L-A \#S-A-E \#B-R-A-S-I-L \#2-0-1-8..

O verbo dos exemplos acima é o verbo "criar", que é classificado como um verbo simples, sem concordância. Quadros e Karnopp (2004) apresentam em seu trabalho a maneira na qual os verbos se flexionam na Libras. Primeiramente, deve-se diferenciar os tipos de verbos: os sem concordância e os com concordância. Aplicando no exemplo (9), entendemos, portanto, que o verbo "criar" não exige flexão ou movimentos direcionais.

Portanto, destacando o trecho <CRIAR CLARO PROCEDIMENTO> da glosa elaborada pelas autoras, é possível observar que, apesar de não exigir flexão, seus argumentos são identificados. Desse modo, caso a oração possua um verbo simples sem concordância, podemos identificar sua flexão a partir do sujeito da oração, o qual será seu primeiro argumento, pois esse tipo de verbo respeita a estrutura canônica da Libras.

Nas glosas, os verbos direcionais são marcados da seguinte forma <MARIA 1ENTREGAR2 JOÃO>, considerando que "entregar" é um verbo com concordância, por possuir dois argumentos. No exemplo mencionado, o sujeito (e primeiro argumento) é Maria, pois refere-se à pessoa que faz a ação; já o objeto é João (sendo também o segundo argumento). Portanto, o verbo "entregar" vem acompanhado da numeração 1 e 2, assim o número 1 fica ao lado do sujeito e o número 2, ao lado do objeto (BRITO, 1995).

Em consonância com Pimenta \& Quadros (2008), a flexão temporal na Libras não é incorporada ao verbo, sendo marcada a partir da organização dos sinais na linha temporal, ou a partir da utilização de sinais que remetem ao tempo, como "hoje", "agora", "passado", "futuro", entre outros adjuntos adverbiais temporais.

Nas glosas fornecidas pelo VLibras, os verbos foram flexionados apenas de maneira temporal. Como foi possível observar no exemplo (8), os verbos foram acompanhados da palavra "FUTURO". Assim, apesar de o tradutor não ter incorporado todos os estilos de flexão verbal, a flexão temporal, remetendo ao futuro, foi marcada corretamente.

No mais, há diversos tipos de flexão verbal na Libras, os quais podem ser divididos, segundo Quadros \& Karnopp (2004, p. 111-112), em: 
V. 11 (3)

32-51

set-dez

2021 pessoa: mudando as referências no verbo; número: indicando singular, plural, etc; grau: distingue tamanhos, distâncias, etc; modo: apresenta como seria a ação do verbo; reciprocidade: indica a relação verbal; foco temporal: mostra aspectos temporais tais como duração de tempo, repetição, etc; aspecto tributivo: indica aspectos específicos (QUADROS \& KARNOPP, 2004, p. 111-112).

A representação da flexão na Libras é feita de maneira a explorar os aspectos espaciais. Dá-se, portanto, por meio da repetição de sinais, da marcação de pontos no espaço, da organização espacial etc.

Além disso, também foi observado que a desinência verbal referente à terceira pessoa do plural permanece na datilologia do aplicativo, como pode ser verificado nos exemplos a seguir:

(10) Texto original da Revista de Ciências Humanas:

Por meio de uma narrativa densa e viva, o pesquisador pode oferecer oportunidade para a experiência vicária, isto é, pode levar os leitores a associarem o que foi observado naquele caso a acontecimentos vividos por eles próprios em outros contextos.

(11) Glosa VLibras:

\#M-E-I-O \#D-E \#N-A-R-R-A-T-I-V-A \#D-E-N-S-A \#V-I-V-A \#P-E-S-Q-U-I-S-A-D-O-R \#P-O-D-E-R \#O-F-E-R-E-C-E-R \#F-U-T-U-R-O \#O-P-O-R-T-U-N-I-D-A-D-E \#P-A-R-A \#E-XP-E-R-I-E-N-C-I-A \#V-I-C-A-R-I-A \#I-S-T-O \#S-E-R \#P-OD-E-R \#L-E-V-A-R \#L-E-I-T-O-R \#A-S-S-O-C-I-A-R-E-M \#S-E-R \#P-A-S-S-A-D-O \#O-B-S-E-R-V-A-D-O \#N-A-Q-U-E$\mathrm{L}-\mathrm{E} \quad \# \mathrm{C}-\mathrm{A}-\mathrm{S}-\mathrm{O} \quad \# \mathrm{~A}-\mathrm{C}-\mathrm{O}-\mathrm{N}-\mathrm{T}-\mathrm{E}-\mathrm{C}-\mathrm{I}-\mathrm{M}-\mathrm{E}-\mathrm{N}-\mathrm{T}-\mathrm{O}$ \#V-I-V-I-D-O \#E-L-E \#P-R-Ó-P-R-I-O \#O-U-T-R-O-S \#C-O-N-T-E-X-T-O

(12) Glosa das autoras:

NARRATIVA DENSA PODER OFERECER EXPERIÊNCIA \#V-I-C-A-RI-A PODER AJUDAR LEITOR ASSOCIAR TEMA PASSADO OBSERVAR COM EXPERIÊNCIA VIDA CONTEXTO VÁRIOS

Como observado no exemplo (12), ao organizar uma glosa, os verbos se mantêm no infinitivo e não possuem morfemas de desinência ou flexão integrados a ele, pois estes são marcados por movimentos direcionais ou apontamentos. Como destacado por Goebel \& Cordenons (2001), uma das características dos verbos na Libras é que eles são representados no infinitivo nas glosas e, desse modo, as desinências verbais são perdidas. 
No exemplo (10), notamos que na língua portuguesa há a desinência verbal "-em" referente à terceira pessoa do plural. Porém, no exemplo (11), a desinência se mantém na glosa apresentada pelo aplicativo. A partir das informações apresentadas, é possível constatar que a presença da desinência verbal "-em" nas datilologias do VLibras, própria da flexão de infinitivo para terceira pessoa do plural, é equivocada e não segue os parâmetros da gramática da Libras.

Portanto, a partir da análise da flexão verbal nas frases fornecidas pelo VLibras, entendemos que há alterações relativas aos pressupostos apresentados por Quadros \& Karnopp (2004) sobre a representação dos verbos em Libras. Como visto, os verbos na Libras sofrem um processo de flexão diferente dos verbos em português, pois, enquanto na Libras o verbo pede argumentos que o acompanham e adicionam noção de pessoa e número, em português existe a adição de uma desinência no verbo para representar esse significado. Assim, é necessário avançar nos estudos gramaticais que irão contribuir para a melhoria do sistema de automatização da tradução da Libras para a língua portuguesa.

\section{VLIBRAS e a organização sintática da Libras}

Um dos principais fatores analisados por este trabalho foi a diferença da organização sintática da Libras e da língua portuguesa, ou seja, a maneira com que as palavras se organizam na sentença em cada uma das línguas. Assim, detectamos que todas as sentenças organizam os sintagmas de forma padronizada. Vejamos os próximos exemplos:

(13) Texto original da Revista de Ciências Humanas:

Este estudo se apresenta como uma tradução comentada de um poema em língua brasileira de sinais - Libras para a língua portuguesa.

(14) Glosa do VLibras:

\#E-S-T-E \#E-S-T-U-D-O \#A-P-R-E-S-E-N-T-A-R \#C-O-M-O \#T-R-A-D-U-Ç- $\widetilde{A}-\mathrm{O}$ \#C-O-M-E-N-T-A-D-A \#P-O-E-M-A \#L-IN-G-U-A \#B-R-A-S-I-L-E-I-R-A \#S-I-N-A-L-L-I-B-R-A-S \#P-A-R-A \#L-I-N-G-U-A \#P-O-R-T-U-G-U-E-S-A 
V. 11 (3)

32-51

set-dez 2021
(15) Glosa das autoras:

ESTUDO ESTE APRESENTAR TRADUÇÃO EXPLICADA POEMA LINGUA BRASILEIRA DE SINAIS LIBRAS LÍNGUA PORTUGUESA

A partir dos exemplos acima percebemos que a forma padrão de organização sintática do aplicativo é SVO, seguindo a ordem da frase do texto original em português. Quadros, Pizzio \& Rezende (2008) apontam que a ordem canônica dos sintagmas na Libras também é SVO, como na frase "ESTUDO ESTE APRESENTAR TRADUÇÃO", no exemplo (15). Assim como na língua portuguesa, a ordem dos sintagmas em Libras pode ser alterada sem tornar a frase agramatical. Porém, essa reorganização ocorre com mais frequência do que na língua portuguesa.

Assim, temos construções OSV, que ocorrem a partir da incorporação de expressões não manuais e marcas de concordância. Há também a ordem SVO, fruto da topicalização, que também possibilita a omissão dos argumentos dos verbos, como por exemplo, do verbo $<$ 1DOAR2 $>$, já explicado anteriormente.

Durante o processo tradutório, a escolha pela reorganização dos sintagmas da oração deveria ser guiada por uma estratégia semântico-pragmática, seguindo a intenção do falante - se ele gostaria de chamar atenção para algum determinado tópico da frase ou de apagar os argumentos do verbo. A escolha por uma dessas construções também pode se basear na incorporação das expressões não manuais, se o tradutor quiser adicionar mais ou menos elementos não manuais na tradução.

Ao levar em consideração a discussão sobre a ordem dos sintagmas na Libras e em português, apresentada no referencial teórico deste artigo, bem como os resultados sobre a organização sintática mostrada pelo aplicativo VLibras, entendemos que neste há uma priorização da ordem sintática própria do português.

Como apresentado por Lefevere e Bassnett (1990), traduzir um texto não consiste apenas na mudança de palavras de uma língua para a outra. Muitas vezes, o processo tradutório também abarca adequações sintáticas, e o caso do português e da Libras é ainda mais delicado devido ao fato de serem línguas de modalidades diferentes (QUADROS\& KARNOPP, 2004). Portanto, a não adequação sintática das sentenças pode acarretar no português sinalizado, como foi o caso dos exemplos (8), (11) e (14). 
Assim, sendo o VLibras uma ferramenta que objetiva traduzir textos do português para a Libras, o uso do português sinalizado não é ideal, pois a tradução não é plenamente atendida, devido ao não seguimento da estrutura gramatical da língua de sinais. É importante que haja o aprimoramento de softwares que façam a tradução considerando os aspectos sintáticos de ambas as línguas. Então, deve-se alimentar o sistema com informações linguísticas de ambas as línguas. Para isso, é necessário debruçar-se em trabalhos como este, que, ao discutir mais pormenorizadamente as diferenças sintáticas entre as línguas, contribui para que sejam realizados os devidos aprimoramentos.

Pontuação na tradução do português para a Libras

Em relação à marcação de pontuação, observamos que o avatar marca as pontuações também por meio de datilologia: o ponto de interrogação, com a soletração da palavra "interrogação", e o ponto de exclamação, com a soletração da palavra "exclamação". Dentre o corpus selecionado para tradução do avatar, encontramos apenas a marcação dessas duas pontuações. Além disso, apenas o texto da Revista de Ciências Humanas apresentou ambos os sinais. Por essa razão, trazemos aqui apenas o exemplo deste artigo.

(16) Texto original da Revista de Ciências Humanas:

Quais as estratégias utilizadas por tradutores para (re)criar uma poesia em português escrito com a mesma intenção do texto da língua de sinais, essencialmente visual e imagética?

(17) Glosa do VLibras:

\#Q-U-A-L \#E-S-T-R-A-T-E-G-I-A \#T-R-A-D-U-T-O-R \#P-AR-A \#R-E-C-R-I-A-R \#P-O-E-S-I-A \#P-O-R-T-U-G-U-E-S \#E-S-C-R-I-T-O \#C-O-M \#M-E-S-M-A \#I-N-T-E-N-Ç- $\widetilde{A}-\mathrm{O}$ \#T-E-X-T-O \#L-I-N-G-U-A \#S-I-N-A-L \#E-S-S-E-N-C-I-A-L$\mathrm{M}-\mathrm{E}-\mathrm{N}-\mathrm{T}-\mathrm{E} \quad \# \mathrm{~V}-\mathrm{I}-\mathrm{S}-\mathrm{U}-\mathrm{A}-\mathrm{L} \quad \# \mathrm{E} \quad \# \mathrm{M}-\mathrm{A}-\mathrm{G}-\mathrm{N}-\mathrm{E}-\mathrm{T}-\mathrm{I}-\mathrm{C}-\mathrm{A} \quad \# \mathrm{I}-\mathrm{N}-\mathrm{T}-$ $\mathrm{E}-\mathrm{R}-\mathrm{R}-\mathrm{O}-\mathrm{G}-\mathrm{A}-\mathrm{C}-\tilde{\mathrm{A}}-\mathrm{O}$.

(18) Glosa das autoras:

ESTRATÉGIAS TRADUÇÃO UTILIZADAS OBJETIVAR CRIAR POESIA PORTUGUÊS SIGNIFICADO IGUAL LIBRAS. ESTRATÉGIAS QUAIS? 
V. 11 (3)

32-51

set-dez

2021

O grande desafio em que focamos foi o de criar processos para ensinar a máquina a fazer uma tradução mais próxima da glosa das autoras. As sentenças interrogativas possuem diversas particularidades além da reestruturação sintagmática, pois esta envolve questões de expressões não manuais. Uma grande discussão para os autores que estudam este tipo de tradução é a dificuldade do avatar em incorporar tais expressões.

Na Libras, a pontuação é marcada pelas expressões não manuais, a partir das expressões faciais e corporais. Dentre essas expressões, temos os movimentos de cabeça (afirmativo ou negativo), a direção do olhar, a elevação das sobrancelhas, a elevação ou o abaixamento da cabeça, o franzir da testa e movimentos com os lábios para indicar negação ou para diferenciar os tipos de interrogação (QUADROS \& KARNOPP, 2004).É possível que uma mesma sentença tenha mais de uma marcação não manual, como negação, dúvida, afirmação, entre outras. Além disso, a sua ausência pode deixar uma sentença agramatical, pois as expressões não manuais são um importante constituinte da gramática da Libras.

Compreendemos que ensinar a máquina a ler as pontuações demandará inúmeras atualizações e estudos acerca da estrutura frasal, juntamente com a pragmática do discurso. Por isso, é importante que haja trabalhos com a mesma finalidade deste, mapeando as dificuldades dos aplicativos, problematizando-as, buscando soluções etc. Assim como feito neste estudo, é importante a consulta da literatura básica gramatical da Libras nos momentos de criação e de aprimoramento de tecnologias de tradução automática.

Como pode ser observado nos três tópicos teóricos deste estudo, as questões englobando a gramática de cada língua são muito delicadas e sofrem mudanças, pois a língua é baseada na interação semânticopragmática, e os ordenamentos frasais podem sofrer modificações pelo contexto e objetivo do falante, como é o caso da topicalização (NEGRÃO, 2017; BRITO, 1995). Mas mesmo nesses casos, as línguas seguem padrões que a partir de estudos podem ser desvendados e adicionados ao VLibras.

Assim, reconhecemos que o intuito do aplicativo em marcar a pontuação da frase a partir da sinalização é uma boa alternativa para suprir essa carência em um primeiro momento Porém, é de suma importância que se estudem modos de alimentar o avatar para compensar essa deficiência. 


\section{Considerações finais}

No presente trabalho analisamos a tradução fornecida por um aplicativo de tradução automática, com o intuito de responder à seguinte pergunta: quais são as adequações sintáticas necessárias para uma transposição linguística entre a Libras e o português?

Os resultados deste trabalho apontam para três aspectos encontrados na tradução: (i) a flexão verbal; (ii) a organização sintática; e (iii) a pontuação apresentada. A análise desses pontos aponta para uma adição mais aprofundada das especificidades linguísticas da Libras no avatar. Em especial, apontamos ainda haver uma priorização da estrutura gramatical do português em relação à Libras. Essa característica pode ser aprimorada por meio do estudo da literatura básica, a qual foi trazida e apresentada neste estudo nos tópicos teóricos.

Procuramos analisar a tradução fornecida pelo aplicativo a partir da discussão de Lefevere e Bassnett (1990). Para eles, a tradução deve respeitar as especificidades das línguas envolvidas, uma vez que a tradução de uma obra também envolve um processo bicultural e bilíngue. No caso da problematização discutida neste trabalho a respeito da tradução para Libras, deve-se considerar o fator cultural e visual dessa língua, que possui grande influência em sua expressão linguística. Assim, ao traduzir um texto de uma língua-fonte para uma língua-alvo, este deve passar por um entendimento cultural.

Acreditamos que as adequações sintáticas necessárias na tradução estão ligadas diretamente ao reconhecimento da Libras como língua e não linguagem, possuidora de uma gramática própria e independente do português. Desse modo, para adequar a tradução que apresenta traços da cultura da língua portuguesa para a Libras, é de suma importância a alimentação do avatar com sinais, adequação à sintaxe espacial e aos processos de formação de sinais.

Ainda, entendemos que há uma carência sobre a consideração dos aspectos linguísticos da Libras no software. O aplicativo apresentou estranhamentos na tradução referente ao português sinalizado, empréstimos linguísticos, linguagem de ouvintes e aspectos formais. O uso em escala da datilologia caracterizou um empréstimo linguístico do português, e a mistura dos fatores linguísticos de ambas as línguas acarretou no português sinalizado, pois a tradução deixou de ser entendível pelos usuários do português e da Libras. 
V. 11 (3) 32-51 set-dez 2021

Este trabalho é de suma importância porque afeta os pontos cruciais na literatura básica sobre os aspectos da Libras. Portanto, esses pontos devem ser revisados para podermos usufruir do aplicativo de forma correta, como para tradução em sala de aula, atividades de pesquisa, tradução de textos, busca por palavras específicas, entre outras funções que o aplicativo pode desempenhar.

Além disso, esse trabalho deve ser realizado por toda a equipe que integra a criação do avatar, pois uma das grandes demandas observadas é a melhoria do programa que faz a tradução automática, que é um trabalho a ser realizado em conjunto por linguistas e os criadores do programa que faz a tradução. Para isso, deve-se ter em mente as diferenças linguísticas entre o português e a Libras e o fato da língua não ser algo padronizado, e sim variável de acordo com o contexto.

No mais, ao longo do desenvolvimento da pesquisa, foi possível ampliar significativamente os conhecimentos acerca das questões que permeiam pontos da linguística do português e da Libras e da aplicação de conceitos linguísticos que envolvem a tradução, além do funcionamento dos softwares de tradução. É de grande importância a continuidade de pesquisas como esta para uma melhora significativa do processo tradutório automático.

\section{Referências}

BAGNO, M. A língua de Eulália: novela sociolinguística. 17 ed. $5^{\text {a }}$ reimpressão. São Paulo: Contexto, 2017.

BECHARA, E. Moderna gramática portuguesa. 37. Ed. Rio de Janeiro: Nova Fronteira, p. 334-335, 2009.

BEZERRA, E. P. et. al. Projeto. Projeto Suíte VLibras: um olhar considerando acessibilidade e arquitetura da informação. 2016. Disponível em: <http:// repositorios.questoesemrede.uff.br/repositorios/handle/123456789/3255> Acesso em: 30 jun. 2020.

BRITO, L. F. Por uma gramática de línguas de sinais. Tempo Brasileiro, 1995.

CANÇADO, M. Posições argumentais e propriedades semânticas. DELTA: Documentação de Estudos em Lingüística Teórica e Aplicada, v. 21, n. 1, p. 23-56, 2005.

DE SOUZA CABRAL, N. E. et al. Projeto de um sistema de suspensão para um veículo tipo Fórmula SAE elétrico. The Journal of Engineering and Exact Sciences, v. 5, n. 4, p. 308-314, 2019.

GOebel, M.; CORDEnOnsI, A. Z. Proposta de um Autômato Finito Determinístico para a Glosa Português-Libras. In: Brazilian Symposium on 
Computers in Education (Simpósio Brasileiro de Informática na EducaçãoSBIE). 2001. p. 262-271.

ITS BRASIL (Instituto de Tecnologia Social). Pesquisa Nacional de Tecnologia Assistiva. São Paulo: ITS BRASIL/MCTI-SECIS, 2012, p. 68. Disponível em: <http://www.santoandre.sp.gov.br/pesquisa/ebooks/368505.pdf> Acesso em: 11 jan. 2021.

LEFEVERE, A.; BASSNETT, S. Introduction: Prousts Grandmother and the Thousand and One Nights: The Cultural Turn, in Translation Studies. Translation, History and Culture. London/NY: Pinter, 1990, p. 1-13.

MAGNANI, J. G. C.. "Vai ter música?":: para uma antropologia das festas juninas de surdos na cidade de São Paulo. Ponto Urbe. Revista do núcleo de antropologia urbana da USP, n. 1, 2007.

NEGRÃO, E. V; SCHER, A.P.; VIOTTI, E. de C. Sintaxe: Explorando a estrutura da sentença. In José Luiz Fiorin (Org.). Introdução à Linguística - II. Princípios de Análise, São Paulo: Contexto, 2003.

NEVES, M. H. M. A gramática funcional. São Paulo: Martins Fontes, 1997.

PIMENTA, N.; QUADROS, R. M. Curso de LIBRAS 1-Iniciante. rev. e atualizada. Porto Alegre: Editora, 2008.

QUADROS, R. M. de; PIZZIO, A. L.; REZENDE, P. L. F. Língua Brasileira de Sinais II. Universidade Federal de Santa Catarina, 2008. Disponível em <https://libras.ufsc.br/colecaoLetrasLibras/eixoFormaca>. Acesso em: 2 ago. 2021.

QUADROS, R. M.; KARNOPP, L. Língua de Sinais Brasileira - Estudos Linguísticos. Porto Alegre: Artmed, 2004.

RAMOS, C. R. História da Datilologia. 2008. Disponível em:<http://www. editora-arara-azul.com.br/pdf/artigo3.pdf>Acesso em: 17 set. 2020

SEGALA, R. R; DE QUADROS, R. M.; SOUZA, S. X . Tradução intermodal, interlingual e intersemiótica na direção Português - Língua Brasileira de Sinais (Libras): desafio normativo, descritivo e performático Surdo ao ensino e aprendizagem de Tradução e Interpretação de Língua de Sinais (TILS). In.

Estudos da Língua Brasileira de Sinais. Florianópolis: Editora Insular, 2018,p. 149-163.

SILVA, M.D.; ALBRES, N. A. Tradução comentada do poema em língua brasileira de sinais "amor à primeira vista". Revista de Ciências Humanas, Viçosa, ano 2018, n. 2, ed. 1, p. 1-16.

SOUZA E SILVA, M. C. P. de; KOCH, I. V. Linguística aplicada ao português: sintaxe. 16.ed.São Paulo: Cortez, 2011.

STOKOE, W. Sign and Culture: A Reader for Students of American Sign Language. Silver Spring, MD: Listok Press, 1960.

STUMPF, M. R.; QUADROS, R. M. de. Estudos da Língua Brasileira de Sinais. Florianópolis: Editora insular, 2018, p. 238, v. 4. 